This item was submitted to Loughborough's Research Repository by the author.

Items in Figshare are protected by copyright, with all rights reserved, unless otherwise indicated.

\title{
DePlan: a tool for integrated design management
}

PLEASE CITE THE PUBLISHED VERSION

PUBLISHER

(C) Elsevier Science B.V.

LICENCE

CC BY-NC-ND 4.0

\section{REPOSITORY RECORD}

Choo, Hyun Jeong, Jamie W. Hammond, Iris D. Tommelein, Simon A. Austin, and Glenn Ballard. 2019. "Deplan: A Tool for Integrated Design Management". figshare. https://hdl.handle.net/2134/3875. 
This item was submitted to Loughborough's Institutional Repository (https://dspace.lboro.ac.uk/) by the author and is made available under the following Creative Commons Licence conditions.

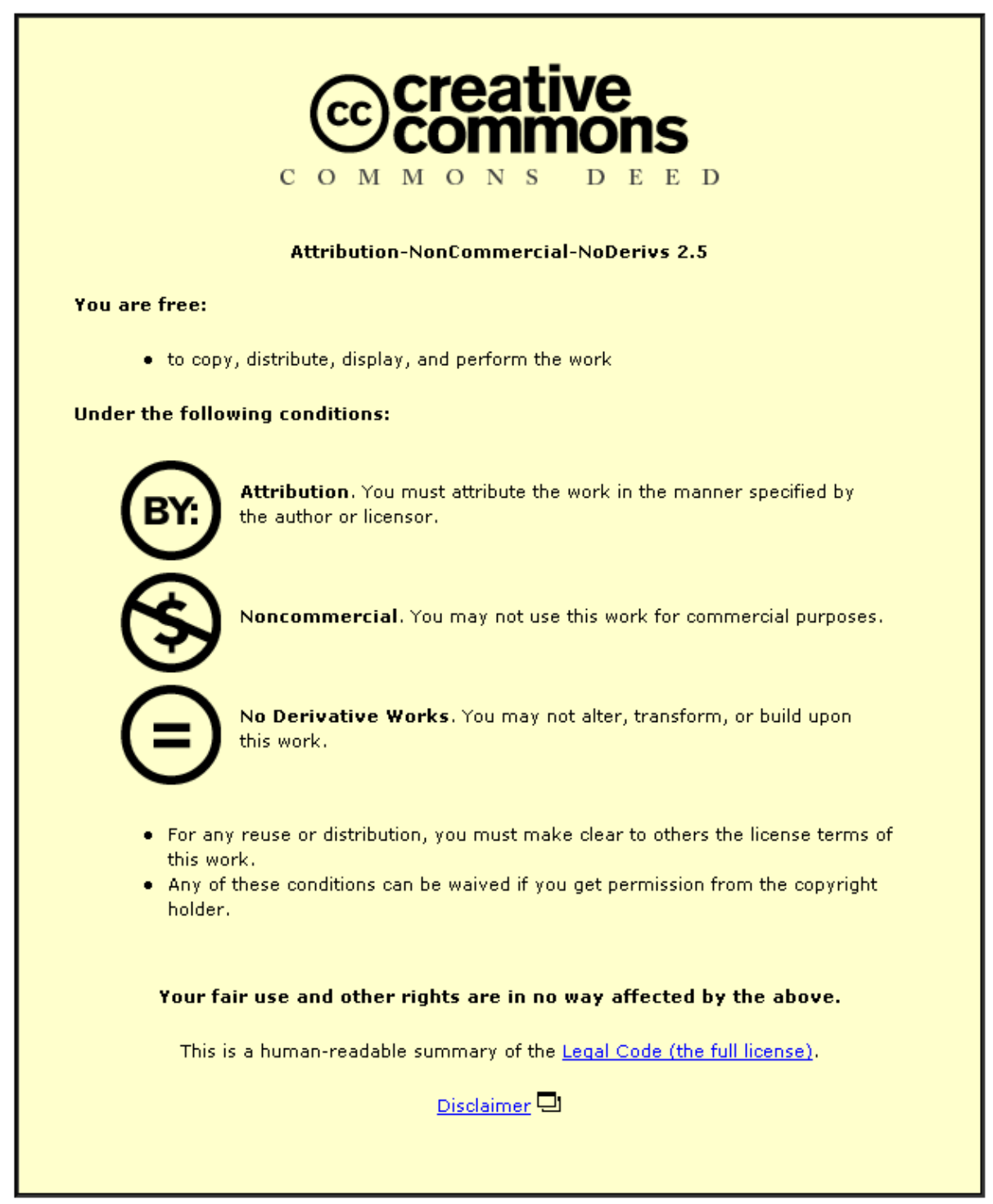

For the full text of this licence, please go to: http://creativecommons.org/licenses/by-nc-nd/2.5/ 


\title{
DEPLAN: A TOOL FOR INTEGRATED DESIGN MANAGEMENT
}

\author{
Hyun Jeong Choo ${ }^{1}$, Jamie Hammond ${ }^{2}$, Iris D. Tommelein ${ }^{3}$, Glenn Ballard ${ }^{4}$ and Simon A. \\ Austin $^{5}$
}

\begin{abstract}
The iterative and information-intensive nature of the design process during detail design phases makes it hard to plan and schedule design work using computer tools for conventional project management. The success of design projects depends on the quality of the available information. Having the right information at the right time is crucial. This paper proposes DePlan as a method for integrated design management, i.e. for planning, scheduling, and controlling design activities during the detail design phase. DePlan integrates two techniques, namely ADePT (Analytical Design Planning Technique) andExtended WorkPlan Last Planner, each involving a software tool.. ADePT implements the dependency structure matrix (DSM) analysis method and helps identify the iterative processes and the planning strategy for managing them. Last Planner is a production management philosophy that focuses on scheduling and controlling design activities. Combined as DePlan, these techniques help planners generate quality plans, i.e., plans that express what is ready for execution by sequencing activities in the right order, identifying informational and resource requirements ahead of design execution, and by scheduling only activities that have met these requirements. This collaborative research has
\end{abstract}

$1 \quad$ Ph.D. Candidate, Constr. Engrg. and Mgmt. Program, Civil and Envir. Engrg. Dept., 215 McLaughlin Hall \#1712, Univ. of California, Berkeley, CA 94720, choohj@ce.berkeley.edu

2 Research Assistant, Department of Civil and Building Engineering, Loughborough University, Loughborough, Leics, LE11 3TU, FAX +1509 223981, j.w.hammond@lboro.ac.uk

3 Associate Professor, Civil and Envir. Engrg. Department, 215-A McLaughlin Hall, Univ. of California, Berkeley, CA 94720-1712, 510/643-8678, FAX 510/643-8919, tommelein@ce.berkeley.edu

4 Director of Research, Lean Construction Institute, and Adjunct Associate Professor, Constr. Engrg. and Mgmt. Program, Civil and Envir. Engrg. Dept., Univ. of California, Berkeley, CA 94720, ballard@ce.berkeley.edu

5 Professor of Structural Engineering, Department of Civil and Building Engineering, Loughborough University, Loughborough, Leics, LE11 3TU, FAX +1509 223981, s.a.austin@lboro.ac.u 
successfully developed the DePlan approach and associated computer software and tested them on a typical office building.

Key-Words

Design Management, ADePT, WorkPlan, Last Planner, Production Management, Planning, Scheduling, Control, Dependency Structure Matrix. 


\section{INTRODUCTION}

In recent times there has been a growing understanding of the importance of effective design management to ensure a co-ordinated building design is developed within budget, and to ensure the smooth running of the project. AEC clients are seeking major reductions in the cost of buildings, which can only be achieved by closer integration between the design and construction functions in the product cycle, as has occurred in other engineering sectors (such as the automobile and manufacturing industries). A key aspect is the capability to plan and manage design effectively, taking into account the iterative nature of the process and changing needs of the project stakeholders.

Current practice in the planning, management and control of the design process is focused on the design deliverables that are listed at the start of each stage of the design process. The tendency is then to plan the design process backwards from the date when these deliverables are due to be released to the client or contractor. A master programme is produced and distributed to the design team, who then plans their work within the framework of the master programme.

This approach assumes that design information is made available and communicated between the project participants as required, either informally or formally via drawings and design reviews. The objective is to get the right information, to the right person at the right time, but experience shows that this is not often the case. Design should be planned, managed and controlled around the flow of information, rather than deliverables, if a co-ordinated and effective solution is to be found. This is a fundamental insight which is increasingly being recognized by the construction industry. The other key point is that design activity, unlike construction, is highly inter-related and finding a suitable sequence that minimizes wasteful rework is difficult. Planners responsible for design are also hampered by the limitation of current project management software, all of which is based on the critical path method and consequently cannot deal with inter-related tasks (like design), only sequential activities.

The application of ADePT (Analytical Design Planning Technique) in building projects has resulted in improved planning effectiveness by allowing design managers to focus on the flow of 
information between design tasks (Austin et al. 1999a, 1999b, 1999c, 2000). By focusing on information flow rather than deliverables, an optimal design sequence can be achieved.Furthermore, ADePT allows the planner to determine a design strategy that best fits the problem involving, for example, concurrent working, targeted solution workshops and timely design reviews..

Effective planning of the design process is the first step in improving design management, however, if not carefully controlled, design teams may be tempted to revert back to more traditional methods of management, leading to significant inefficiencies due to poor information flow, and the inappropriate allocation of resources. The Last Planner Technique is a production management philosophy that focuses on the organisation and management of the project operation (Ballard \& Howell 1994a, 1994b and Ballard, 1997). This technique is designed to reduce the amount of uncertainty that exists within the project process by managing the inherent variability that lies within it. Although originally devised for manufacturing, the technique has been adapted here to the design process. Last Planner helps the project team to systematically create lookaheads and weekly work plans before the start of design to track the status of completed work.

This paper introduces DePlan (Hammond et al. 2000), an integrated approach to managing the design process that combines the strategic nature of ADePT with the operational approach of Last Planner (Figure 1). DePlan encompasses design planning, scheduling, and control:

- planning - determining the required activities to meet the design criteria, the relationship between the activities, and an optimal sequencing.

- scheduling - assessing the status on their readiness to be performed, assigning resources, and determining the start time, duration, and completion time for each of the activities.

- control - assessing the status of activities after completion of workand calculating resource usage in terms of time and cost.

Unlike traditional interpretations, the latter also encompasses the make-ready process (Ballard and Howell 1994a, 1994b), i.e., determining what needs to be achieved and focusing on those needs to make activities ready to be performed.

The paper also describes the implementation of DePlan through a combination of software tools. ADP (Analytical Design Planner) was already being developed to support ADePT, whilst 
extended WorkPlan was developed specifically for the application of Last Planner to design management, by modifying an earlier program, Work Plan, created for the construction process.

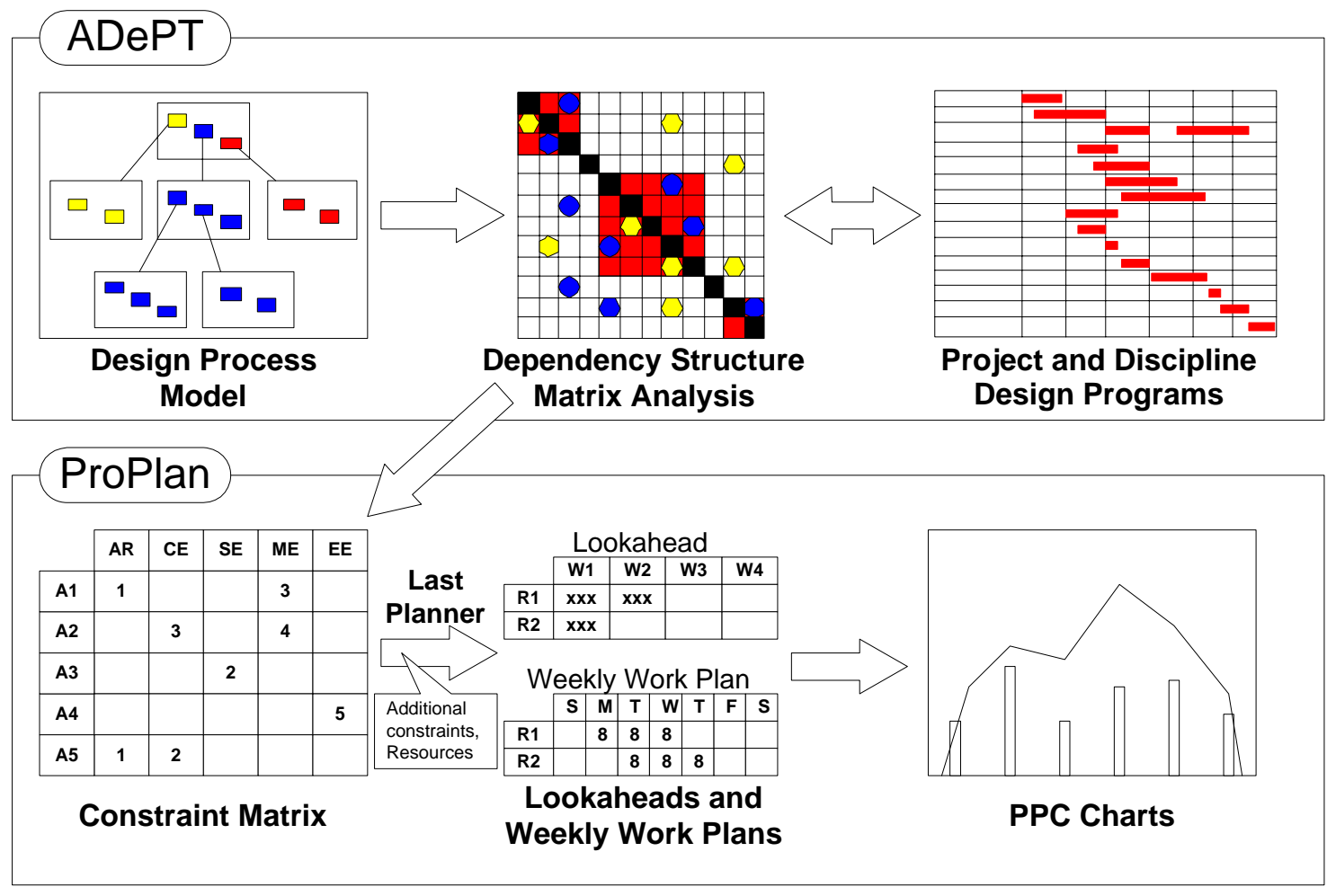

Figure 1. DePlan

\section{PLANNING WITH DEPLAN}

\subsection{Method}

The first three steps of DePlan involved modeling the design process, analysing the dependency structure matrix and creating the project schedule. Building a design process model, involves to defining the design tasks and their information requirements. The second stage is to optimize the sequence of the tasks defined in the first stage using Dependency Structure Matrix (DSM) analysis. DSM analysis identifies iteration within the design process. It then groups iterative tasks into a sub-matrix and sequences these tasks depending on their relationships with tasks in the rest of the matrix. The third stage is to develop a design schedule based on the activity sequence from the second stage by assigning resources. Development of the design schedule might reveal unforeseen conditions or constraints that require recalculation of the activity 
sequencing. In these cases, the repeated application of DSM analysis and design schedule development is necessary.

\subsection{Design Process Model}

ADePT usually uses a generic design process model (Austin et al. 1999a) to develop a projectspecific design process model. The process model is based on UK industry practices and has been applied to building projects varying in value between $£ 2 \mathrm{M}$ and $£ 180 \mathrm{M}$. A modified version of IDEF $_{0}$ (Error! Reference source not found.) can be used to graphically represent the design process.

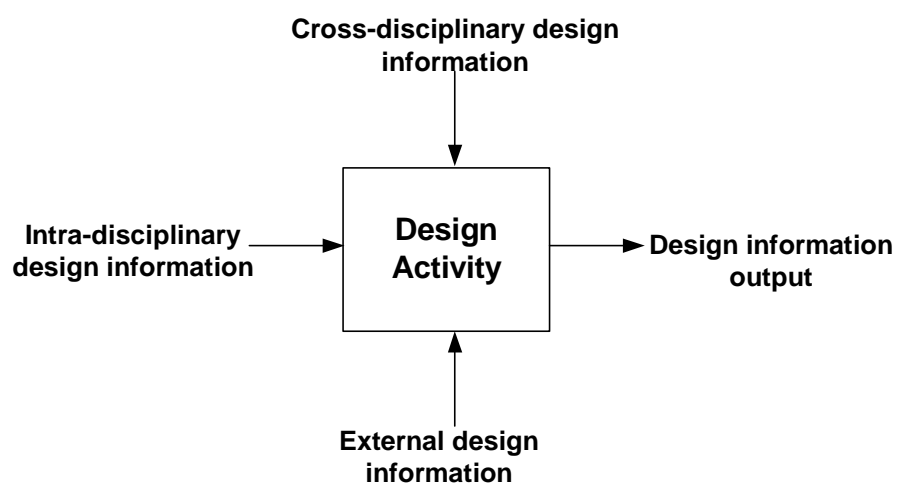

Figure 2. IDEF0v Notation

ADePT's current generic process model for detailed design contains a hierarchy of tasks belonging to five major building design disciplines: architecture, civil, structural, mechanical, and electrical engineering. Each activity is hierarchically detailed into systems, subsystems, and design tasks to articulate the information requirements and the output. Experience has shown that the generic model contains more than $90 \%$ of the tasks and dependencies need to define a specific building (Austin et al 1999a)

\subsection{Dependency Structure Matrix Analysis}

Steward (1981) developed the Dependency (or Design) Structure Matrix to improve the efficiency of solving complex problems. He proposed that a complex problem could be divided into contributing sub-problems by using a matrix to represent interrelationships between tasks. 
DSM has been applied to various research projects since. McCord and Eppinger (1993) applied DSM to engineering problems, including semi-conductor design and automotive engineering design. Huovila et al. (1995) applied DSM to building design problems. A significant number of DSM research projects are currently underway (MIT DSM Research Team 2000a). These projects are investigating the representation of various data types in DSM, and are categorized as component-based, team-based, activity-based or parameter-based DSM (MIT DSM Research Team 2000b).

Figure 2Figure 4 is a sample of a dependency structure matrix showing ten design tasks before the matrix is optimized. The matrix has the same sequencing of tasks in the row and column headings. This sequencing implies the order for task execution. Each cross mark " $\mathrm{X}$ " in a row represents dependence of that task on the task noted in the column heading. For example, Task A requires the results of Task B and Task H. In the current sequencing as shown (left), Task B and Task H appear in rows below Task A: they will therefore be done after Task A. Accordingly, their output data will not be available when Task A starts. For their output to be available earlier, these tasks should be re-sequenced so as to finish before Task A.

If re-sequencing is not possible based on the current plan, then one of the strategies for the designer engaged in Task $A$ is to accelerate through the iterations in a dedicated team meeting. The designers responsible for Task A, Task B, and Task $\mathrm{H}$ can collectively try to reach a solution that satisfies the requirements for all three tasks. However, this team meeting strategy can only work if other required information is obtainable, i.e., the output of Task F for Task B and the output of Task $\mathrm{C}$ for Task H. This, in turn, might create a need to bring the designers responsible for Task $\mathrm{F}$ and Task $\mathrm{C}$ to the meeting as well, and so forth. This strategy may become impractical when too many designers need to be involved. In fact inspection of the initial matrix sequence reveals that all 10 tasks will be involved in the solution of the first (A). A team meeting strategy can better be employed when an optimal sequencing and subtask groups are obtained first.

Another strategy is to delay the task that is lacking necessary information, perhaps shifting the burden to others responsible for dependent tasks that are able to better estimate, perhaps with a lower penalty. This passive strategy may work as long as other dependent designers do not delay their tasks. 
Another alternative is to make educated guesses or design to the worst-case scenario. If guesses were made, they will need to be revisited later to see if the assumptions were correct, when output from Task B and Task H is available. If not, Task A will need to be carried out anew, with additional information available at that time. If designed to the worst-case scenario, the solution can result in an unnecessarily big safety factor, which is not only costly but can also be translated into waste.

None of these strategies is attractive at this stage as they involve too much risk or rework. The power of a DSM tool is that a more efficient sequence can be found by applying an optimisation algorithm.

\begin{tabular}{|l|l|l|l|l|l|l|l|l|l|l|}
\hline & A & B & C & D & E & F & G & H & I & J \\
\hline Task A & & X & & & & & & X & & \\
\hline Task B & & & & & X & & & & \\
\hline Task C & & & & & X & & & & $\mathbf{X}$ & \\
\hline Task D & & & $\mathbf{X}$ & & & $\mathbf{X}$ & & & & \\
\hline Task E & & & & & & & & $\mathbf{X}$ & \\
\hline Task F & X & & & & & & & \\
\hline Task G & & & & & & & & & X \\
\hline Task H & & & $\mathbf{X}$ & & & & & & \\
\hline Task I & & & & $\mathbf{X}$ & & & $\mathbf{X}$ & & \\
\hline Task J & & & & & & $\mathbf{X}$ & & & \\
\hline
\end{tabular}

\begin{tabular}{|c|c|c|c|c|c|c|c|c|c|c|}
\hline & B & $\mathrm{F}$ & $\mathrm{J}$ & G & $E$ & I & C & $\mathrm{H}$ & & D \\
\hline Task B & & $X$ & & & & & & & & \\
\hline Task F & x & & & & & & & & & \\
\hline Task J & & & & $x$ & & & & & & \\
\hline Task G & & & $x$ & & & & & & & \\
\hline Task E & & & & & & $x$ & & & & \\
\hline Task I & & & & & $x$ & & & $x$ & & \\
\hline Task C & & & & & $x$ & $x$ & & & & \\
\hline Task H & & & & & & & $x$ & & & \\
\hline Task A & $x$ & & & & & & & $\mathrm{x}$ & & \\
\hline Task D & & $x$ & & & & & $x$ & & & \\
\hline
\end{tabular}

Figure 24. Example of DSM Analysis (a) before and (b) after Optimisation Any " $\mathrm{X}$ " mark above the diagonal line of the matrix represents dependence on a task that is sequenced later than the task in each row (and therefore involves feedback as possible iteration). A more optimal sequence will have a lower number of " $X$ " marks above the diagonal line. Figure 2Figure 4 (b) shows the result of the DSM analysis, i.e., an optimized matrix. The number of " $\mathrm{X}$ " marks to the right of and above the diagonal line has decreased from eight to four. Accordingly, the number of design iterations is likely to decrease. Figure 2Figure-4 (a) also reveals three sub-matrix blocks. Each block represents tasks with reciprocal dependence. They may have to be performed concurrently.

The DSM analysis stage of the ADePT methodology allows the planner to classify the level of dependency between tasks (Austin et al. 1996) The classification represents three levels of dependencies of information,eg, A, B, and C, where. Level A is the most critical and level C is the least. The level of dependency is based on 1) how dependent the task is on the information, 2) how sensitive the task is to the change of the information, and 3) how easy the information 
can be estimated. The level of dependency between the same two tasks may vary from project to project and from planner to planner and must therefore be considered carefully.

Figure 5 shows part of a real project matrix from the Plan Weaver software. It demonstrates the level of complexity of the design of construction products. Note that here the three dependency levels are signified by number $(3,2,1)$ not letter.

Figure $\underline{3} 5$. Typical project matrix (ie PlanWeaver)

\subsection{Design Programming}

The partitioned matrix can be exported into a planning tool to generate a design schedule. In order to schedule a task, its start/end dates, duration, and resource requirements need to be determined. The sequence of tasks is taken from the DSM and exported to a conventional project management program., However, the blocks of interrelated tasks require special attention, as the sequencing within the blocks themselves is not based solely on dependencies but requires a strategic decision. To determine the appropriate strategy, the planner needs to study the tasks in the blocks to see whether the relationships between the tasks actually are reciprocal. It may be possible to eliminate reciprocal dependencies by breaking tasks into several sub-tasks and relating these sub-tasks sequentially.One strategy might be to position all tasks to start at the same time (Figure 4Figure 6 ) or to finish at the same time, and, in either case, execute them concurrently. Other strategies are discussed in Austin et al. (1999b).

This final stage of ADePT produces the master design programme which defines the overall planning strategy for the project. This is based on the logic of the information dependency of the design process and will also have been integrated with the proposed construction programme.

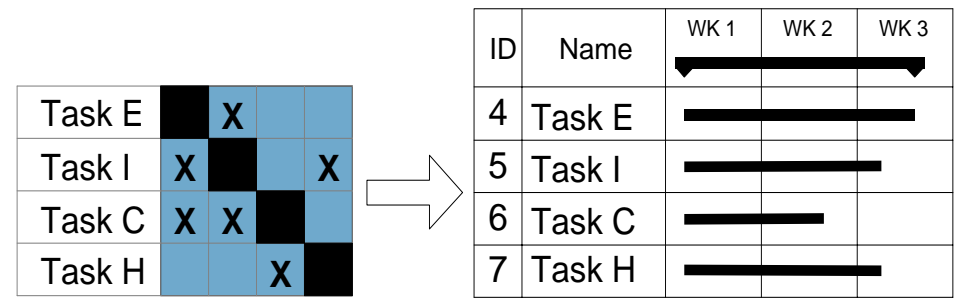

Figure 46 . Scheduling Iterative Blocks of Tasks 


\subsection{ADP and PlanWeaver}

Several computer programs have been developed over the last seven years to implement ADePT. Initial development of DePlan was done using our Analytical Design Planner (ADP) software, Version 4.1. The latest is a commercial product called PlanWeaver, developed by BIW Technologies, which is delivered by ASP (application service provider) and DSM analysis and exchanges the results into several common project management tools to undertake the scheduling of tasks. It has been used on a wide range of projects and can quickly implement this part of DePlan.

\section{SCHEDULING AND CONTROLLING}

\subsection{Last Planner}

A production plan is created based on certain assumptions, e.g., assumption on availability of resources, information, permits, weather, etc. Therefore the ability to execute this plan is heavily constrained by how much the actual situation resembles the assumed situation. However, the actual situation does not always match the assumed situation. Therefore, before the plan can be executed, these constraints must be explicitly checked to ensure a successful execution. Therefore what CAN actually be done must be selected from what SHOULD be done.

The Last Planner methodology proposes exactly that - a production plan should be created by selecting only the work that CAN be done from the work that SHOULD be done (Error! Reference source not found.). For a more detailed explanation of the Last Planner methodology, refer to Ballard and Howell (1994a, b, 1998).

\section{Error! Objects cannot be created from editing field codes.}

Figure 57: Last Planner Planning Process (Ballard and Howell 1994a)

One means to determine what work CAN be done is to describe the constraints that are preventing the work from starting and finishing without interruptions. It is not only important to determine the requirements for starting work but also to determine whether the requirements remain satisfied throughout the duration of the work. Developing the constraint list not only allows the planner to determine what work CAN be executed but more importantly what NEEDS to be done in order to make a SHOULD into a CAN.

.Extended WorkPlan, like ADePT, allows the user to generate a schedule from the ground up, but, as an alternative, it can also import the optimized order of design tasks from the ADePT 
DSM (Figure 6Figure 8). By importing the output matrix, Extended DePlan automatically enters the activities list, the disciplines responsible for each activity and the informational dependencies into its database. An ASCII file format was chosen initially as an interface between ADP and WorkPlan programs.

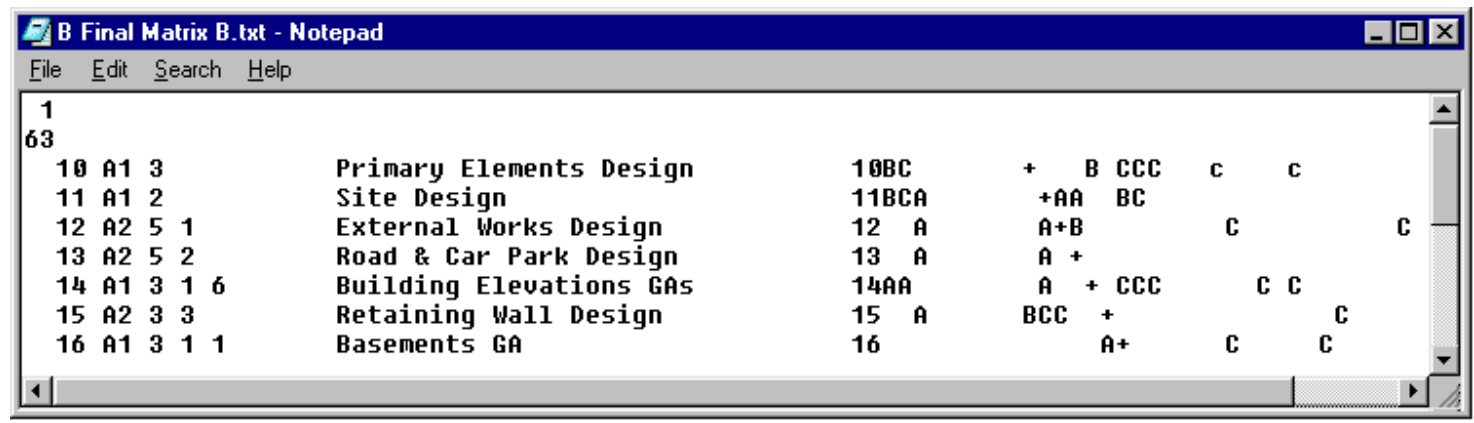

Figure 68. Sample Output Matrix Generated from ADePT

\subsection{Activity Definition Model for Constraint Analysis}

The activity definition model (ADM) (Figure 9) facilitates the development of the list of activities and their constraints. ADM is an input-process-output representation that can be used to represent a design or a construction process. The inputs are composed of DIRECTIVES, PREREQUISITES, and RESOURCES. A DIRECTIVE is defined as an "instruction or order issued by a last planner to direct workers on what to do and possibly when or how to do it." A PREREQUISITE is defined as "work done by others on materials or information that serves as an input or substrate for your work." A RESOURCE is defined as "labor or instrument of labor, including tools, equipment, and space." Unsatisfied needs are constraints that prevent the process from being executed. The CRITERIA are a subset of directives that measure the extent to which the output resulting from process execution is acceptable. If the result is not acceptable, rework will result. The model cannot only be used to determine what the constraints are, but also to determine whether the activity needs to be exploded, i.e., broken down into a set of smaller processes, each having its own set of inputs and CRITERIA. 


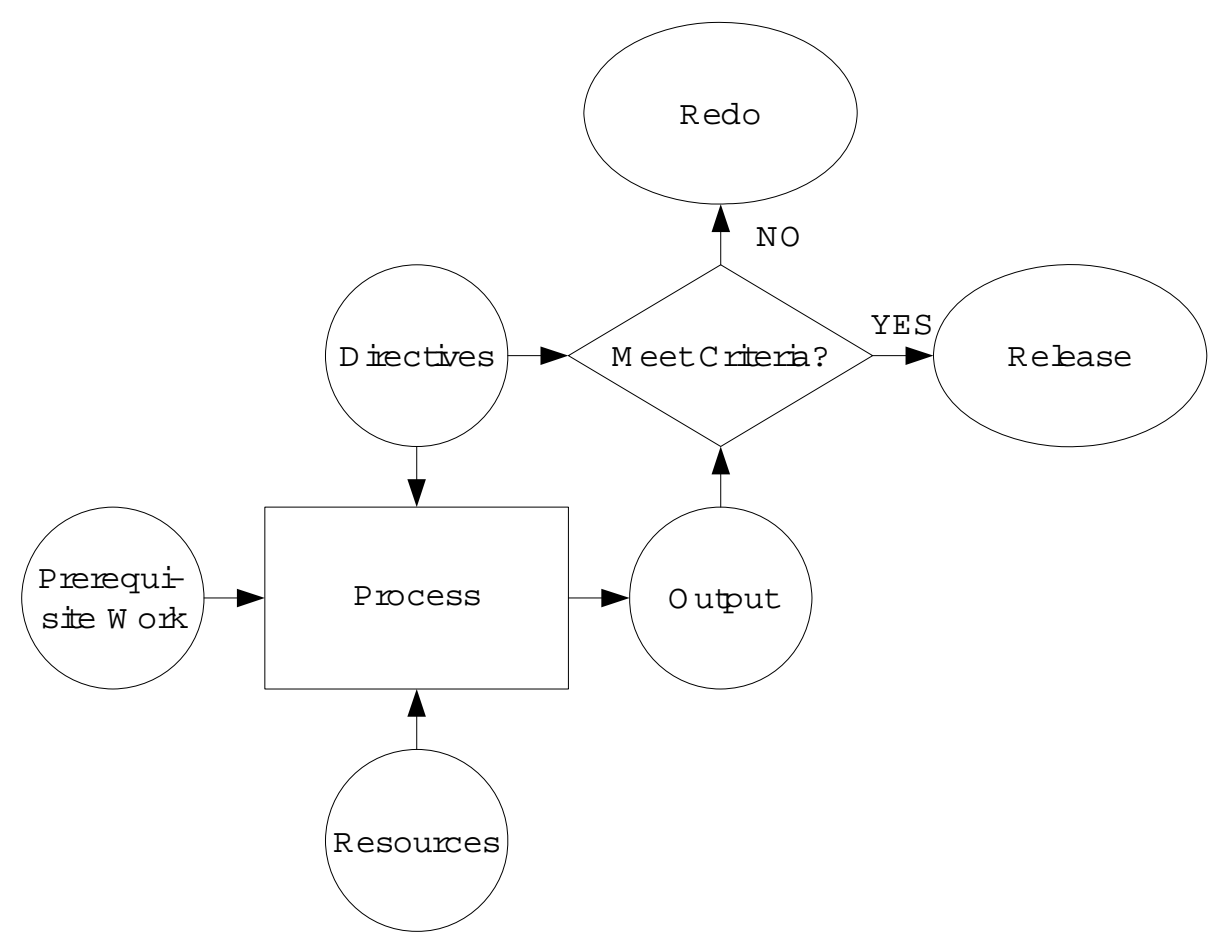

Figure 9. Activity Definition Model (Lean Construction Institute 1999)

\subsection{Extended WorkPlan Software Development}

Extended WorkPlan has been developed by the research team to link the process models and DSM analysis output to the Last Planner scheduling and control methodology. In order to determine what CAN be done, the constraints need to be specified and checked (NEEDS). Extended WorkPlan assists the planner in systematically articulating constraints that fall into five categories: Contract, Engineering, Samples, Resources and Design Constraints. These parameters were chosen after reviewing the original categories in WorkPlan against the constraints likely to arise in the management of design processes.

Directives explain what is required and how to achieve those requirements. They can be mostly captured in the Constraint List form in terms of contracts, engineering documents and samples, termed "Contract”, “Engineering”, and "Samples”. . The “Contract” category refers to constraints such as contractual finalization, commercial constraints, permits and subcontracting agreements.. The "Engineering” category constraints arise from other engineering disciplines such as construction management and planning/scheduling supervisors. The "Samples" category includes instances where design is constrained by agreements to provide samples or mock-ups 
whilst "Resources" relate to the means to achieve the requirements specified by the directives (i.e., people, tools, equipment, space, and money). The latter includes not only means for direct production, but also supporting functions such as supervision, accounting, planning/scheduling and drafting.. In Extended WorkPlan, designers and supporting services are the resources that are actively managed. This means that the planner must specify what type of designers and supporting services are needed, and, in addition, determine when and how long they will be required on each process. Therefore, Extended WorkPlan maintains information regarding these resources that the planner oversees or has the means to request services from. The "Design Constraints" category refers to design constraints in Extended WorkPlan. It specifies the information required before design can start. This information can either be manually input by the user or imported from the ADePT software. In the latter case, it is automatically restructured to generate the constraint matrix (Figure 8Figure 12).

Each design activity corresponds to a work package in Extended WorkPlan. The number in each box of the constraint matrix refers to the design constraints that are under the responsibility of that discipline. These constraints are outstanding (i.e., unattained or not yet satisfied) informational constraints that must be met before start of the design activity in order for each activity to be carried out successfully. Any unsatisfied constraint will end up delaying the start of the activity. However, by categorizing constraints by discipline, the planner can easily see the current status of the constraints and which disciplines are involved.

Figure $\underline{711 .}$ Constraints List

Numbered cells in the matrix are linked to the detailed constraint list. For example, clicking "1" in the civil engineering discipline (CE) for the work package C1000-16 will bring up the detailed description of that constraint (similar to Figure 7Figure 11 but containing constraints for the selected work package and discipline) for which the CE discipline is responsible. The description contains two sections. The top section refers to the constraints that have been met. The bottom section refers to the constraints that have not yet been met (e.g., design information that still is undetermined or unavailable). The number " 1 " corresponds to the number of outstanding constraints which is the number of filled-out rows in the bottom section of the screen. The top section, which represents the constraints that have been met, allows the planner to keep track of 
what constraints have been satisfied. By knowing what information is available and what information is needed, the planner can better react when unforeseen changes occur to design activities. The planner can also add constraints if they are identified after information in AdePT's design process model has been imported, or later, during project execution.

\begin{tabular}{|c|c|c|c|c|c|c|c|}
\hline Constrain & & & & & & & \\
\hline Work $\mathrm{Pa}$ & Assignment & Arch & CE & SE & ME & EE & \\
\hline C1000-10 & Primary Elements Design & 4 & & 1 & & & \\
\hline C1000-11 & Site Design & 2 & 2 & & & & \\
\hline C1000-12 & External Works Design & 1 & 2 & 1 & & & \\
\hline C1000-13 & Road \& Car Park Design & 1 & & & & & \\
\hline C1000-14 & Euilding Elevations GAS & 5 & & 1 & & & \\
\hline C1000-15 & Retaining Wall Design & 2 & 2 & & & & \\
\hline C1000-16 & Basements GA & & 1 & 1 & & & \\
\hline & & & & & & 㭌 & $\rightarrow$ \\
\hline
\end{tabular}

Figure 112 . Constraint Matrix based on Figure 6Figure 8

As explained earlier, design constraints provide a partial list of the constraints that must be satisfied in order to successfully execute the design production. Other types of constraints can also be specified using the Work Package Constraints form (Figure 7Figure 11).

When all constraints for a design activity are satisfied (CAN) or are expected to be satisfied, this activity can be released for scheduling using the Work Package Release form (Figure 9Figure 13). The released activities form the basis for development of a plan, which is done some time before activities get executed. Release is not automatic because activities may still have outstanding constraints at the time of release and planners must anticipate whether these outstanding constraint(s) can be expected to be met when the activity is to start.

Figure 10Figure 14 shows a weekly work plan that is automatically generated based on resource assignments. For the purpose of tracking, the constraints that are expected to be met in the course of the planned week are automatically printed in the "make ready needs" section. For example, in order to start "C1000-002: External Walls Finishes” on August 28 ${ }^{\text {th }}$, “C1000-152: 
External Walls Details" needs to be finished by the "Architectural discipline (Arch)" as previously planned.

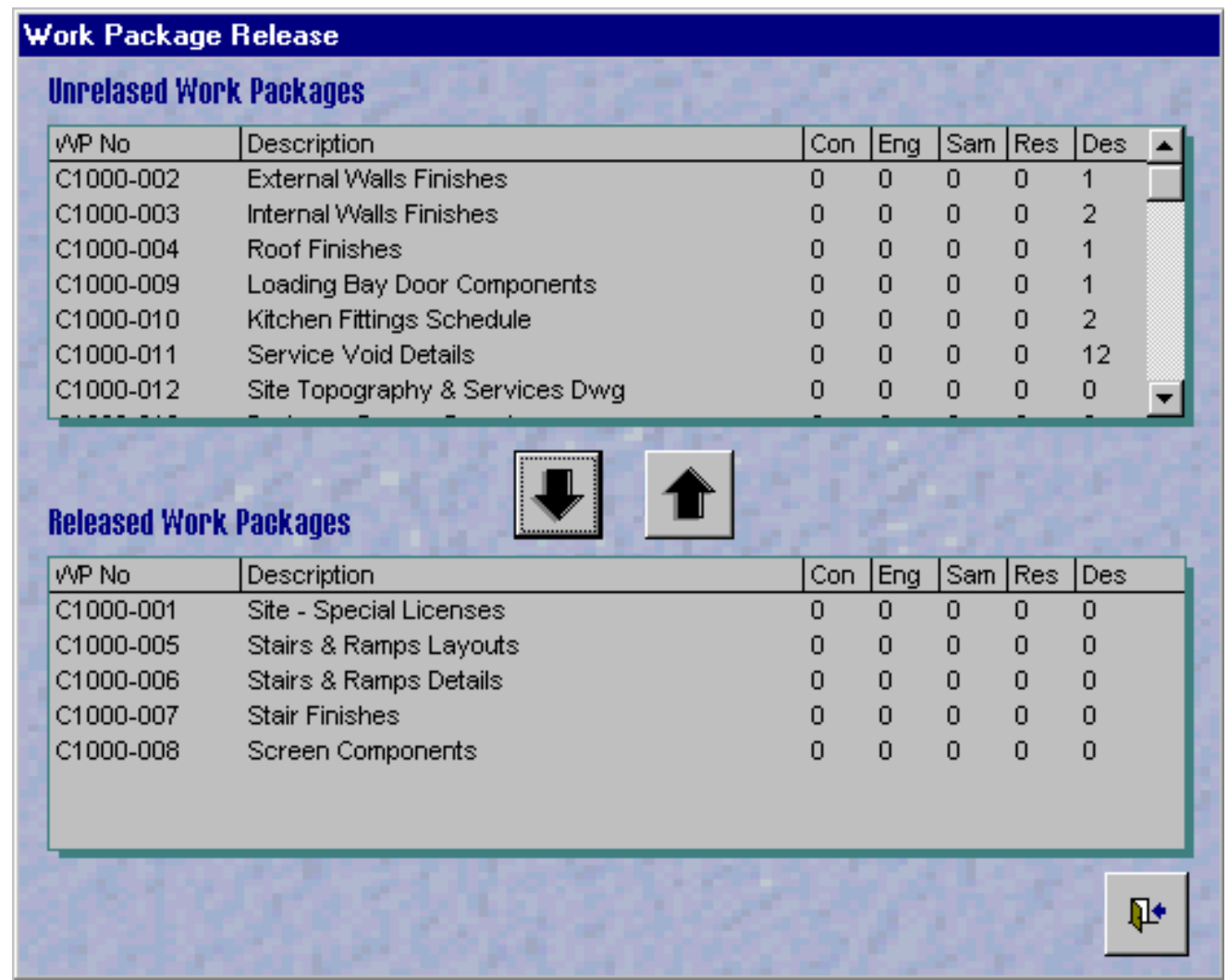

Figure 913. Work Package Release Form

Date Prepared : $\quad$ Monday, August 28, 2000

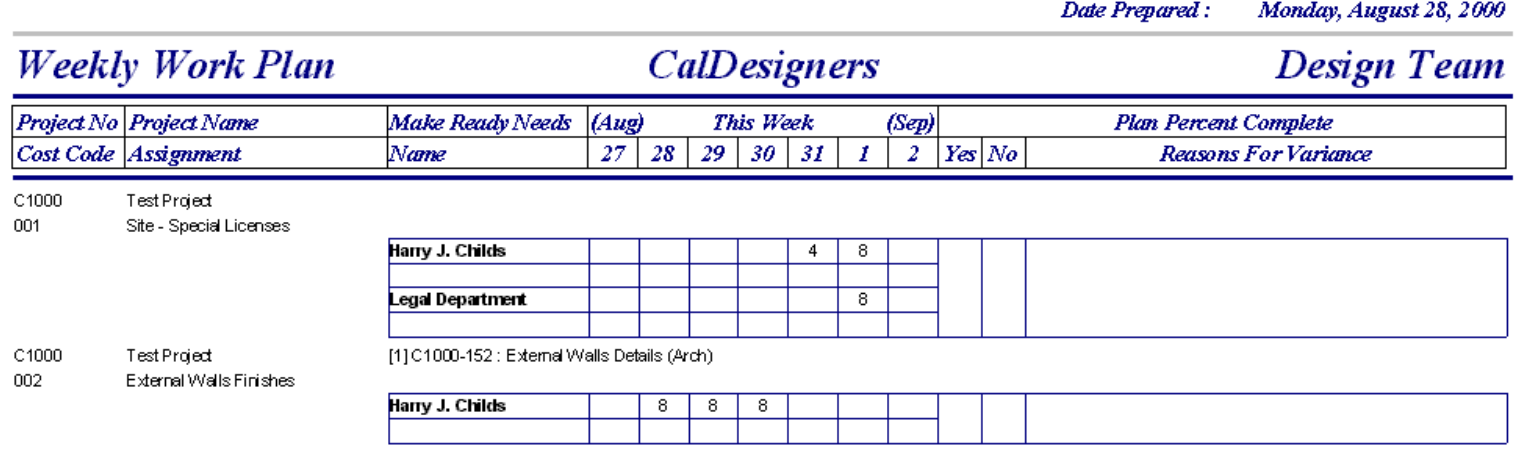

Figure 1014. Weekly Work Plan Generated from Extended WorkPlan

After each week, the designers and the supporting services need to enter the actual number of hours they spent on each design activity and check whether or not their assignments were completed within the planned week. The data on actual hours spent serve as a basis for automatically creating the timesheets and the cost report. If the assignments are not completed as 
planned, they must detail the reasons for variance. This data is used to calculate Percent of Plan Completed (PPC) (Ballard and Howell, 1998) to measure the reliability of the planning system. PPC is calculated by dividing the number of completed assignments by the total number of assignments each week. PPC itself is a good representation of the reliability of a planning system. Analyzing the reasons for failure of the plan and learning from this analysis is even more valuable, because it allows the planner to take action in order to prevent the same mistakes from reoccurring in the future. Extended WorkPlan shows the PPC for the last six weeks (Figure 11Figure 15) so that the planner can see not only this week's evaluation but, more importantly, whether the planning reliability has improved. Extended WorkPlan also tracks the reasons for failure and generates a-reasons-for-variance report.

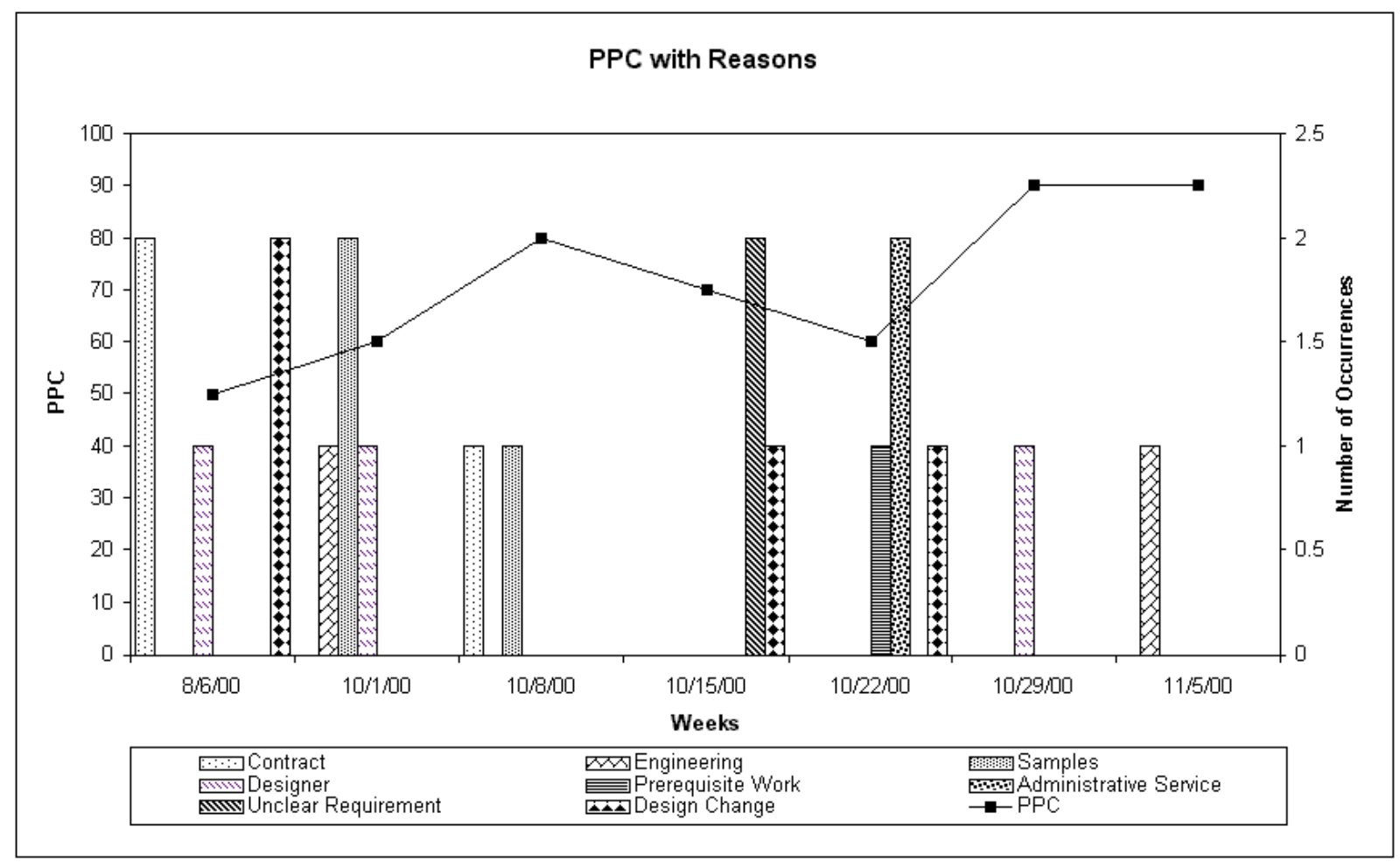

Figure 1115. PPC Chart with Reasons for Failure

\section{DISCUSSION AND CONCLUSIONS}

DePlan presents a powerful concept for design management, combining strategic planning via a design process model and DSM analysis to determine the optimal design production sequence with operational scheduling and controlling of individual design tasks that are free from constraints and hence have a high probability of being completed on time. 
DePlan is being evaluated by project teams in the US and UK to support integrated design management. The data captured in DePlan will be a valuable model, reflecting industry practices regarding the description of activities and the relationships between them. Six seminars presenting DePlan as an approach to managing design has been well received in the UK. Seminar presentations to 70 senior Design and Project Managers has resulted in drives to incorporate the tools and techniques in their design management practice. In particular, this approach was seen to be an important way forward for improving Design and Build project effectiveness, due to its highly collaborative nature.

The development of DePlan poses a number of questions when considering the provision of a fully integrated solution to design process management, which are discussed below.

1 What is the impact of DePlan and associated design decisions on the design process as a whole? The current design process model is hierarchical and design work is decomposed according to a traditional discipline-based work breakdown structure. Tasks at the lowest level (functional primitive tasks) have a one-to-one relationship with design activities to be scheduled. However, these activities lose that hierarchical relationship once they are optimized in the DSM analysis. DSM-sequenced activities may suggest a different breakdown structure to result in an even more efficient organization of work. Tsao et al. (2000) describe the concept of 'work structuring,' which concerns itself with deciding who is in the best position to perform what task. DePlan may prove to be useful for experimentally identifying natural boundaries of work (one component of work structuring) based on various sequencing and breakdown criteria.

2 Is the activity-based DSM, as implemented in ADePT, the most appropriate use of DSM for the design of architectural/engineering/construction (AEC) products? Additional research must be conducted to investigate, for instance, the use of component-based, team-based, or parameterbased DSM (Browning 2001). Work is currently being undertaken by one of the authors into the structuring of design teams by team-based DSMs that involve clustering rather than sequencing activities.

3 Is it possible to determine whether or not a design activity is completed if its duration extends beyond one week? As units of hand-off or solutions are generated after the completion of a design activity, the amount of work to-be-done and done are hard if not impossible to determine. Yet, determining activity completion is important for the successful application of the Last Planner method. It is, therefore, important that activities be defined in terms of what 
information they release to others rather than based on the deliverables (e.g., 30\%, 60\%, 90\%, or 95\% complete drawings). This information does not need to be the final decision or solution, but rather a set of alternatives remaining to be considered, thus allowing (some) others to proceed with their work, so long as their product is consistent with that set.

4 Is there a relationship between the use of DSM and set-based design? Set-based design advocates the carrying-forward of sets of alternatives until the "last responsible moment" at which time the designer must narrow the set of alternatives or commit to one alternative. Setbased design creates the possibility of avoiding iteration in the design process. When each discipline presents a set of alternatives to their peers in other disciplines, it is likely that a set intersection will exist that satisfies each discipline's design criteria. By contrast, point-based design is much more likely to cause design iteration, when assumptions made by one discipline yielded a single, point solution that is not compatible with other disciplines' assumptions. ADePT currently supports point-based design as it assumes that a task or a group of tasks is responsible for providing a decision or a solution that is handed-off to other dependent tasks.. Set-based design may be more successful when it is based on clearly defined interfaces between the various disciplines and the products they create, so that various sub-systems can be mixed and matched to achieve better overall systems performance. By contrast, point-based design often allows interface definition to be handled in an ad-hoc fashion. DSM and set-based design thus appear to present competing alternatives to managing design, but it is possible that one is preferred over the other in certain circumstances. As multiple process models are needed to support set-based design, DSM can lend itself as a smaller tool to explore alterative processes.

In conclusion, DePlan offers a combined planning, scheduling and control methodology for integrated design management. Our research has shown how this can be achieved by blending to established methods - AdePT and Last Planner. Prototype software has been developed to verify the approach and undertake validation exercises. The methodology can add vigour and transparency to the management process and provides an opportunity to achieve greater integration of design in the supply chain.

\section{ACKNOWLEDGEMENTS}

This work has been undertaken as a Lean Design research project at the University of California at Berkeley, USA, and as part of the Integrated Collaborative Design (ICD) research project at 
Loughborough University, UK. This research has been funded in part in the USA by a grant from the University of California and in the UK by grants GR/M11240 of the EPSRC, DETR and industry. Any opinions, findings, conclusions, or recommendations expressed in this paper are those of the authors and do not necessarily reflect the views of UC Berkeley, EPSRC, and DETR.

\section{REFERENCES}

Alarcon, L.F. (editor)(1997). Lean Construction. A.A. Balkema, Rotterdam, The Netherlands, 497 pp.

Austin, S., Baldwin, A. and Newton, A. (1996) "A Data Flow Model to Plan and Manage the Building Design Process” Journal of Engineering Design, Vol. 7., No. 1 pp 3-25

Austin, S., Baldwin, A., Li, B. \& Waskett, P. (1999a). “Analytical Design Planning Technique: a model of the detailed building design process.” Design Studies 20, 279-296.

Austin, S.A., Baldwin, A.N., Li, B. and Waskett, P.R. (1999b). “Analytical Design Planning Technique (ADePT): programming the building design process.” Proc. of Institution of Civil Engineers; Structures and Buildings, Vol. 134, 111-118.

Austin, S., Baldwin, A., Li, B. \& Waskett, P. (1999c). "Analytical Design Planning Technique (ADePT): A Dependency Structure Matrix Tool to Schedule the Building Design Process.” Construction Management and Economics, Vol. 17, 1999, 155-167.

Austin, S., Baldwin, A., Li, B. \& Waskett, P. (2000) Application of the Analytical Design Planning Technique to Construction Project Management. Project Management Journal. 31(2) 48-59

Ballard, G. (1997). “Lookahead Planning: The Missing Link in Production Control.” Proc. $5^{\text {th }}$ Annl. Conf. Intl. Group for Lean Constr., Griffith Univ., Gold Coast Campus, Australia.

Ballard, G. and Howell, G. (1994a). "Implementing Lean Construction: Stabilizing Work Flow." Proc. $2^{\text {nd }}$ Ann. Conf. on Lean Constr., Pontificia Univ. Catolica de Chile, Santiago, Sept., http://www.vtt.fi/rte/lean/santiago.htm, reprinted in Alarcon (1997).

Ballard, G. and Howell, G. (1994b). "Implementing Lean Construction: Improving Downstream Performance." Proc. 2nd Ann. Conf. on Lean Constr., Pontificia Univ. Catolica de Chile, Santiago, Sept., http://www.vtt.fi/rte/lean/santiago.htm, reprinted in Alarcon (1997).

Ballard, G. and Howell, G. (1998). "Shielding Production: An Essential Step in Production Control" ASCE, J. Constr. Engrg. and Mgmt., 124 (1) 18-24. 
Browning, T.R. (2001) “Applying the Design Structure Matrix to System Decomposition and Integration Problems: A Review and New Directions).” IEEE Transactions on Engineering Management, 48 (3) 292-306.

Choo, H.J., Tommelein, I.D., Ballard, G., and Zabelle, T.R. (1999). "WorkPlan: Constraintbased Database for Work Package Scheduling." ASCE, J. of Constr. Engrg. and Mgmt., 125 (3) $151-160$.

Hammond, J., Choo, H.J., Austin, S., Tommelein, I.D., and Ballard, G. (2000). "Integrating Design Planning, Scheduling, and Control with DePlan." Proc. Eighth Annual Conference of the International Group for Lean Construction, IGLC-8, 26-28 July held in Brighton, United Kingdom.

Huovila, P., Koskela, L., Lautanala, M., and Tanhuanpaa, V.P. (1995). "Use of the Design Structure Matrix in Construction.” Proc. $3^{\text {rd }}$ International Workshop on Lean Construction, Albuquerque, reprinted in Alarcon (1997).

Lean Construction Institute. (1999). Lookahead Planning: Streamlining the Work Flow that Supports the Last Planner, Workbook T5, Lean Construction Institute, www.leanconstruction.org

McCord, K.R. and Eppinger, S.D. (1993). Managing the Integration Problem in Concurrent Engineering, Working Paper 359 4-93-MSA, MIT, Sloan School of Management.

MIT DSM Research Team (2000a). The Second MIT DSM International Workshop. September 18-19, Cambridge, MA. http://web.mit.edu/dsm/DSM2000/home.htm.

MIT DSM Research Team (2000b). DSM Tutorial. Massachusetts Institute of Technology, Cambridge, MA. http://web.mit.edu/dsm/Tutorial/tutorial.htm.

Steward, D.V. (1981). Analysis and Management: Structure, Strategy and Design. Petrocelli Books, USA.

Tsao, C.C.Y., Tommelein, I.D., Swanlund, E., and Howell, G.A. (2000). "Case Study for Work Structuring: Installation of Metal Door Frames." Proc. Eighth Annual Conference of the International Group for Lean Construction (IGLC-8), 17-19 July, held in Brighton, UK. 